\title{
Protein kinase $C-\delta$ isoform mediates lysosome labilization in DNA damage-induced apoptosis
}

\author{
NICOLAS PARENT ${ }^{1}$, MAX SCHERER $^{2}$, GERHARD LIEBISCH ${ }^{2}$, \\ GERD SCHMITZ ${ }^{2}$ and RICHARD BERTRAND ${ }^{1,3}$ \\ ${ }^{1}$ Centre de Recherche du Centre Hospitalier de l'Université de Montréal (CRCHUM), \\ Hôpital Notre-Dame and Institut du Cancer de Montréal, Montreal, QC H2L 4M1, Canada; \\ ${ }^{2}$ Institute for Clinical Chemistry and Laboratory Medicine, University of Regensburg, D-93042 Regensburg, Germany; \\ ${ }^{3}$ Département de Médecine, Université de Montréal, Montreal, QC H3C 3J7, Canada
}

Received September 22, 2010; Accepted November 5, 2010

DOI: $10.3892 /$ ijo.2010.881

\begin{abstract}
A lysosomal pathway, characterized by the partial rupture or labilization of lysosomal membranes (LLM) and cathepsin release into the cytosol, is evoked during the early events of 20-S-camptothecin lactone (CPT)-induced apoptosis in human cancer cells, including human histiocytic lymphoma U-937 cells. These lysosomal events begin rapidly and simultaneously with mitochondrial permeabilization and caspase
\end{abstract}

Correspondence to: Dr Richard Bertrand, CRCHUM, Hôpital Notre-Dame and Institut du Cancer de Montréal, 1560 Sherbrooke St. East (Room Y-5634), Montreal, QC H2L 4M1, Canada E-mail: richard.bertrand@umontreal.ca

Abbreviations: $\downarrow \Delta \Psi \mathrm{m}$, loss of mitochondrial inner membrane potential; AO, acridine orange; ASM, acidic sphingomyelinase; ATM, ataxia telangiectasia mutated kinase; cAbl, cytosolic Abelson oncogene homolog 1 kinase; CE, cholesterol ester; CER, ceramide; CNT, control; CPT, 20-S-camptothecin lactone; CRK-L, CT10 regulator of tyrosine kinase isoform L; CS, ceramide synthase; DESP, desipramine; dihSM, dihydro-sphingomyelin; DNA-PK, DNA-protein kinase; FB1, fumonisin B1; FC, free cholesterol; HexCER, hexosylceramide; IP, immunoprecipitation; JNK, Jun amino-terminal kinase; LacCER, lactosylceramide; LAMP-1, lysosomal-associated membrane protein 1; ESI-MS/MS, electrospray ionization/tandem mass spectrometry; LLM, labilization of lysosomal membranes; LPC, lysophosphatidylcholine; p38MAPK, p38 mitogen-activated protein kinase, p73, tumor protein 73; PC, phosphatidylcholine; $\mathrm{PCH}$, phosphorylcholine; PE, phosphatidylethanolamine; PG phosphatidyldiglycerol; PI, phosphatidylinositol; $\mathrm{PKB} / \mathrm{AKT}$, protein kinase $\mathrm{B}$; PKC- $\delta$, protein kinase $\mathrm{C}-\delta$; $\mathrm{PLA}_{2}$, phospholipase $\mathrm{A}_{2}$; PLC, phospholipase C; PLASM, PE-based plasmalogen; PS, phosphatidylserine; ROTT, rottlerin; SEM, standard error of the mean; SPA, sphinganine; SPH, sphingosine; SM, sphingomyelin; TMRE, tetramethylrhodamine ethylester; TNF- $\alpha$, tumor necrosis factor- $\alpha$; UV, ultraviolet

Key words: apoptosis, camptothecin, lysosome, protein kinase C- $\delta$, sphingolipids, electrospray ionization/tandem mass spectrometry activation within $3 \mathrm{~h}$ after drug treatment. Recently, in a comparative proteomics analysis performed on highlyenriched lysosomal extracts, we identified proteins whose translocation to lysosomes correlated with LLM induction after CPT treatment, including protein kinase $\mathrm{C}-\delta(\mathrm{PKC}-\delta)$. In this study, we show that the PKC- $\delta$ translocation to lysosomes is required for LLM, as silencing its expression with RNA interference or suppressing its activity with the inhibitor, rottlerin, prevents CPT-induced LLM. PKC- $\delta$ translocation to lysosomes is associated with lysosomal acidic sphingomyelinase (ASM) phosphorylation and activation, which in turn leads to an increase in ceramide (CER) content in lysosomes. The accumulation of endogenous CER in lysosomes is a critical event for CPT-induced LLM as suppressing PKC- $\delta$ or ASM activity reduces both the CPTmediated CER generation in lysosomes and CPT-induced LLM. These findings reveal a novel mechanism by which PKC- $\delta$ mediates ASM phosphorylation/activation and CER accumulation in lysosomes in CPT-induced LLM, rapidly activating the lysosomal pathway of apoptosis after CPT treatment.

\section{Introduction}

Apoptosis is a controlled process involving many components of the cell, including organelles, such as the mitochondrion, nucleus, endoplasmic reticulum (ER) and lysosome (1). The lysosomal compartment is associated with apoptotic signaling in a wide diversity of cells and with stimuli, such as oxidative stress (2-4), lysomotropic (5-8) and photosensitizing agents (9-11), photodamage (12), serum withdrawal (13), Fas and tumor necrosis factor- $\alpha$ (TNF- $\alpha$ ) ligation (13-15), phospholipid and sphingolipid analogues (16-18), DNA-damaging $(19,20)$ and microtubule-stabilizing agents $(21,22)$, the quinolone class of antibiotics (23), artificial retinoids (24), zinc chloride (25) and silica (26). Although participation of the lysosomal compartment in apoptosis is cell type- and stimuli-specific, a shared feature among all models is the apparition of moderate lysosomal membrane ruptures, referred to here as labilization of lysosomal membranes (LLM), and the subsequent release from the lysosomal lumen to the 
cytosol of lysosomal peptidases, the cathepsins, which contribute to cell death through various targets (27-30).

A number of mechanisms underlying LLM have been proposed, including lipid alterations of lysosomal membrane composition. Indeed, oxidative stress, lysosomal accumulation of redox-active iron and lipid peroxidation chain reaction can destabilize the lysosomal membrane (31). The accumulation of sphingosine (SPH) and lysophosphatidylcholine (LPC) in membranes has been reported to provoke LLM $(16,32,33)$. SPH is a sphingolipid with a long hydrophobic tail and a polar head that acts as a lysomotropic agent with detergent properties (16). In addition, the SPH accumulation can form channels in the membranes (32). In turn, LPC, a phospholipase $\mathrm{A}_{2}\left(\mathrm{PLA}_{2}\right)$-produced lipid metabolite, is capable of eliciting relatively selective damage to lysosomal membranes by changing lysosomal osmotic sensitivity, provoking the entry of potassium ions and leading to the loss of lysosomal membrane integrity (33).

Certain proteins have been reported to induce or protect cells from LLM. It has been suggested that Bax, a proapoptotic member of the Bcl-2 family, can translocate to both the mitochondria and lysosomal membranes in human fibroblasts exposed to the apoptosis-inducing drug, staurosporine. The Bax insertion into lysosomal membranes is believed to provoke LLM (34). Certain studies have suggested a role for $\mathrm{PLA}_{2}$ (35), in destabilizing lysosomes, possibly through the hydrolysis of phospholipids embedded within lysosomal membranes (36) and LPC generation (33). Other studies have proposed that $\mathrm{PLA}_{2}$ and phospholipase C (PLC) can osmotically destabilize lysosomal membranes via a $\mathrm{K}(+) / \mathrm{H}(+)$ exchange process (37-40). Another potential mechanism is that the lysosome-associated apoptosis-inducing protein containing PH and FYVE domains (LAPF) mediates LLM through the phosphorylation and re-localization of p53 to lysosomes in TNF- $\alpha$-treated murine fibrosarcoma cells (41). Finally, the heat shock protein 70 has been described as a stabilizing agent of lysosomal membranes, effectively blocking LLM during diverse apoptotic treatments (42), Bcl-2 has been associated with the inhibition of PLA $\mathrm{P}_{2}$ activation and oxidative stress-induced LLM (43), while Bcl-xL overexpression prevents both the 20-S-camptothecin lactone (CPT)-induced loss of mitochondrial membrane potential $(\downarrow \Delta \Psi \mathrm{m})$ and LLM (19).

Human histiocytic lymphoma U-937 cells are highly sensitive to DNA damage and rapidly die by apoptosis after short treatment with the DNA-damaging drug, CPT, a DNA topoisomerase I inhibitor, that traps transient intermediates of DNA topoisomerase I reactions where enzymes are linked to the 3 ' terminus of a DNA duplex $(44,45)$. The apoptotic death of these cells is associated with the rapid involvement of a mitochondrial and lysosomal pathway, within 2 to $3 \mathrm{~h}$ after drug treatment (19). Recently, using a comparative and quantitative proteomics approach on highly-enriched purified lysosomes obtained from control and CPT-treated human histiocytic lymphoma U-937 cells, we reported that 27 proteins re-localize or de-localize to lysosomes during the very early stages of CPT-induced LLM and apoptosis. Among the validated candidate proteins, protein kinase $C-\delta(P K C-\delta)$ was identified as a protein that rapidly translocates to lysosomes after CPT treatment (46). PKC- $\delta$ is a ubiquitously-expressed isoform of the multigenic family of PKC proteins related to serine/threonine kinase that acts in diverse cellular processes, including cellular proliferation $(47,48)$ and apoptosis $(49-51)$ in a stimulus- and tissue-specific manner. So far, the apoptotic function of PKC- $\delta$ has been associated with its localization and activation of multiple signaling proteins, including Jun amino-terminal kinase (JNK), p38 mitogen-activated protein kinase (p38MAPK), ataxia telangiectasia mutated kinase (ATM), protein kinase B (PKB/AKT), cytosolic Abelson oncogene homolog 1 kinase (cAbl), tumor protein 73 (p73), DNA-protein kinase (DNA-PK), lamin, and scramblase $(52,53)$. PKC- $\delta$, upon phorbol 12-myristate 13-acetate treatment, has been found to rapidly translocate to lysosomes where it phosphorylates and activates acidic sphingomyelinase (ASM), a key enzyme that catalyzes the degradation of membrane-bound sphingomyelin (SM) into phosphorylcholine (PCH) and ceramide (CER) (54). PKC- $\delta$ has also been reported to mediate cytosolic CER accumulation through ASM activation in ultraviolet (UV)-treated cells (55).

In this study, we investigated the role of PKC- $\delta$ translocation to lysosomes in LLM during the early stages of CPTinduced apoptosis. We show that PKC- $\delta$ is required for CPTinduced LLM, as silencing its expression by RNA interference (RNAi) or suppressing its activity with the pharmacological inhibitor, rottlerin (ROTT), prevents CPT-induced LLM in U-937 cells. The PKC- $\delta$ translocation to lysosomes governs lysosomal ASM phosphorylation and activation, and the depression of ASM activity by the pharmacological inhibitor, desipramine (DESP), also prevents CPT-induced LLM. PKC- $\delta$-mediated ASM activation leads to an increase of CER in lysosomes. This accumulation of endogenous CER in lysosomes is a critical event for LLM, given that the suppression of PKC- $\delta$ or ASM activity reduces CPT-mediated CER generation in lysosomal membranes and CPT-induced LLM. These results reveal a novel pathway where PKC- $\delta$ translocation to lysosomes mediates ASM phosphorylation/ activation, CER generation and LLM during the early stages of CPT-induced apoptosis in U-937 cells.

\section{Materials and methods}

Cell line, chemicals, drug treatments and RNAi transfection experiments. The human histiocytic lymphoma U-937 cell line from the American Type Culture Collection (Manassas, VA, USA) was grown in suspension at $37^{\circ} \mathrm{C}$ under $5 \% \mathrm{CO}_{2}$ in RPMI-1640 medium supplemented with $10 \%$ heat-inactivated fetal bovine serum, $100 \mathrm{U} / \mathrm{ml}$ penicillin and $100 \mu \mathrm{g} / \mathrm{ml}$ streptomycin (Gibco-BRL Life Technologies, Grand Island, NY, USA). CPT, ROTT, DESP, fumonisin B1 (FB1) and Histodenz $^{\mathrm{TM}}$ were obtained from the Sigma-Aldrich Co. (St. Louis, MO, USA). Percoll ${ }^{\mathrm{TM}}$ was purchased from GE Healthcare Bio-Sciences AB (Uppsala, Sweden). Acridine orange (AO) and tetramethylrhodamine ethylester (TMRE) were procured from Molecular Probes (Eugene, OR, USA). PKC- $\delta$ peptide substrate was from Biomol International (Plymouth Meeting, PA, USA). All other chemicals were of reagent grade and were purchased from either the SigmaAldrich Co., ICN BioMedicals (Costa Mesa, CA, USA) or other local sources. For drug treatments, U-937 cells were exposed to CPT at a concentration of $1.0 \mu \mathrm{M}$ for the indi- 
cated time. In the reported experiments, pre-incubation with $\operatorname{DESP}(10 \mu \mathrm{M}), \mathrm{FB} 1(10 \mu \mathrm{M})$ or ROTT $(3.5 \mu \mathrm{M})$ was undertaken $1 \mathrm{~h}$ prior to CPT addition. Gene silencing of human PKC- $\delta$ was performed with the following duplex siRNA, sense, 5'-GGCUACAAAUGCAGGCAAUdTdT-3'; and antisense, 5'-AUUGCCUGCAUUUGUAGCCdTdT-3' as reported previously (56). siRNAs and negative control siRNAs were purchased from Thermo Scientific Dharmacon Products (Lafayette, CO, USA). For siRNA transfection, the cells were seeded without antibiotics, grown for $24 \mathrm{~h}$, and transfected with Lipofectamine 2000 (Invitrogen Corp., Carlsbad, CA, USA) according to the instructions of the manufacturer. After $6 \mathrm{~h}$ of transfection, the medium was changed to complete growth medium containing serum and antibiotics, and the cells were grown for $48 \mathrm{~h}$ prior to CPT treatment.

Assessment of $\downarrow \Delta \Psi m$ and LLM. $\downarrow \Delta \Psi \mathrm{m}$ was assessed by TMRE uptake (57). At the indicated times (h) after CPT treatment, $1 \times 10^{6}$ cells were incubated with $100 \mathrm{nM}$ TMRE in complete culture medium for $25 \mathrm{~min}$ at room temperature, washed 5 times and re-suspended in $500 \mu 1$ of ice-cold PBS. They were then subjected to flow cytometry analysis. For LLM assessment, at various times after drug treatment, $1 \times 10^{6}$ cells were incubated with $1.5 \mu \mathrm{M} \mathrm{AO}$ in complete culture medium for $25 \mathrm{~min}$ at $37^{\circ} \mathrm{C}$, washed 5 times and re-suspended in $500 \mu 1$ of ice-cold PBS prior to analysis by flow cytometry (uptake method) $(2,19)$. The loss of TMRE orange fluorescence was measured with the FL2 channel, the loss of lysosomal AO red fluorescence with the FL3 channel and the increase in cytosolic AO green fluorescence was measured with the FL1 channel of a Coulter EPICS XL-MLC flow cytometer. At least 10,000 cells per sample were acquired in the histograms, at least 3 independent experiments were conducted, and the results are expressed as the percentage of cells presenting $\downarrow \Delta \Psi \mathrm{m}$ or LLM.

Immunofluorescence microscopy. Control and CPT-treated U-937 cells were allowed to adhere on glass slides previously treated with BD Cell-Tak ${ }^{\mathrm{TM}}$ (BD Biosciences, Bedford, MA, USA) according to the manufacturer's specifications. Slides were then prepared as described previously (46). The first antibodies used were anti-cathepsin D of mouse origin (C47620, BD Biosciences; $10 \mu \mathrm{g} / \mathrm{ml}$ in $5 \%$ fetal bovine serum in PBS). The second antibodies used were Texas-red linked anti-mouse of goat origin (GE Healthcare BioSciences $A B ; 1: 25 \mathrm{v} / \mathrm{v}$ in $5 \%$ fetal bovine serum in PBS). Images were generated with a Nikon Optiphot-2 microscope equipped with a thermoelectrically-cooled CCD camera (Model DC330E, Dage-MTI Inc., Michigan City, IN, USA) and Clemex Vision software (version 3.0.036, Clemex, Longueuil, QC, Canada).

Electron microscopy. Cells were processed as described previously $(44,45)$. Briefly, the cells were fixed in $0.1 \mathrm{M}$ Millonig's phosphate buffer ( $\mathrm{pH} 7.4,292$ mOsm) containing $2.5 \%$ gluteraldehyde, stained with $2 \%$ uranyl acetate, and dehydrated with several ethanol treatments. The sections (500-700 A) were mounted on copper grids and stained in lead citrate. Samples were examined (JFE Enterprises,
Brookville, MD, USA) by transmission electron microscopy with a Zeiss Em 10 CA microscope.

Analysis of DNA fragmentation. The kinetics of DNA fragmentation were monitored and quantified by DNA filter elution assays, and the results are expressed as percentages of DNA fragmentation $(44,45,58)$.

Subcellular fractionation. The 2-step sequential density gradient centrifugation procedure was modified from the one described by Storrie and Madden (59) and Paquet et al (19) for lysosome isolation. Briefly, control and CPT-treated U-937 cells $\left(5 \times 10^{8}\right)$ were swelled in deionized water for 4 min on ice, and the samples were adjusted by the addition of $220 \mathrm{mM}$ mannitol, $70 \mathrm{mM}$ sucrose, $10 \mathrm{mM}$ Hepes-KOH (pH 7.4) and $1.0 \mathrm{mM}$ EDTA (isotonic buffer). The cells were disrupted by passing the samples 30 -fold through a 26G3/8 needle, and they were subsequently centrifuged at $1,000 \mathrm{x} g$ for $15 \mathrm{~min}$ to pellet unbroken cells and nuclei. Supernatants containing mitochondria, lysosomes and other vesicles were adjusted by the addition of $8 \mathrm{mM}$ calcium chloride and were then centrifuged at $5,000 \times \mathrm{g}$ for $15 \mathrm{~min}$ to pellet the rough ER and mitochondria. The supernatants were then layered on top of the first gradient consisting, from bottom to top, of $2 \mathrm{ml}$ of $35 \%(\mathrm{w} / \mathrm{v}$ ) Histodenz, $2 \mathrm{ml}$ of $17 \%$ (w/v) Histodenz, and $5 \mathrm{ml}$ of $6 \%(\mathrm{v} / \mathrm{v})$ Percoll in isotonic buffer. After centrifugation at $50,500 \times \mathrm{g}$ for $1 \mathrm{~h}$ at $4^{\circ} \mathrm{C}$, a set of 2 discrete bands appeared at the interfaces of $17 / 35 \%$ Histodenz and $6 \%$ Percoll $/ 17 \%$ Histodenz. The upper band, at the $6 \%$ Percoll/17\% Histodenz interface, contained small mitochondria and lysosomes that required separation by the second gradient to obtain pure organelle fractions. This interface was collected and adjusted to $35 \%$ Histodenz by mixing with $80 \%(\mathrm{w} / \mathrm{v})$ Histodenz solution. The sample was then placed at the bottom of the second gradient and overlaid with $2 \mathrm{ml}$ of $17 \%$ Histodenz and $5 \mathrm{ml}$ of $5 \%$ Histodenz. The tube was filled to the top with the isotonic buffer, and centrifuged at 50,500 $\mathrm{x} \mathrm{g}$ for $1 \mathrm{~h}$ at $4^{\circ} \mathrm{C}$. Two distinct bands appeared: The upper one at the $5 / 17 \%$ Histodenz interface contained lysosomes, while the lower one, at the $17 / 35 \%$ Histodenz interface, contained small mitochondria. To pellet the lysosomes, the interface was diluted with the largest possible volume of isotonic buffer and centrifuged at $53,000 \mathrm{x}$ g for $1 \mathrm{~h}$ at $4^{\circ} \mathrm{C}$. The purity of lysosomal preparations was monitored by fluorescence microscopy following in vitro staining with the fluorescent biomarkers, LysoTracker RED/DND-99 (lysosomes), MitoTracker Green/FM (mitochondria), ER-Tracker Red dye (ER) and Hoechst 33342 (nucleus). In parallel, the purified preparations were also validated by fluorescence microscopy and Western blotting using specific antibodies directed against the protein biomarker, lysosomal-associated membrane protein 1 (LAMP-1) (lysosome), VDAC-1 (mitochondria), calnexin (ER) and nucleolin (nucleus). The purity of the lysosomal extracts has been recently documented in detail (46).

Immunoprecipitation (IP) experiments and Western blotting. To prepare total protein extracts, cells were washed twice in PBS, homogenized and lysed in buffer containing $50 \mathrm{mM}$ Tris (pH 7.4), $120 \mathrm{mM} \mathrm{NaCl}, 1 \%$ Triton X-100, $1 \mathrm{mM}$ 
sodium orthovanadate, $2 \mathrm{mM}$ phenylmethylsulfonyl fluoride, $5 \mathrm{mM}$ sodium pyrophosphate and a cocktail of protease inhibitors (Complete ${ }^{\mathrm{TM}}$, Roche Molecular Biochemicals, Laval, QC, Canada) at $4^{\circ} \mathrm{C}$ for $30 \mathrm{~min}$, centrifuged, and the supernatants collected. The same procedure was applied to prepare proteins from purified lysosome pellets. For co-IP experiments, $150 \mu \mathrm{g}$ of purified lysosome proteins were used and $5 \%$ BSA (w/v) was added to the lysis buffer. The supernatants were incubated overnight with primary antibodies $(10 \mu \mathrm{g} / \mathrm{ml})$ at $4^{\circ} \mathrm{C}$. Immunocomplexes were captured with a protein A- and G-sepharose mixture followed by several washes with lysis buffer prior to sodium dodecyl sulfatepolyacrylamide gel electrophoresis. The primary antibodies in the Western blot and co-IP experiments included antiASM rabbit polyclonal (sc-11352; Santa Cruz Biotechnology, Santa Cruz, CA, USA), anti-CT10 regulator of tyrosine kinase isoform L (CRK-L) rabbit polyclonal (sc-319; Santa Cruz Biotechnology), anti-caspase-3 rabbit polyclonal (556425; BD Biosciences), anti-LAMP-1 mouse monoclonal (611042; BD Biosciences), anti-PKC- $\delta$ rabbit polyclonal (SA-148; Biomol International), anti-phospho-(Ser) PKC substrate rabbit polyclonal (2261; Cell Signaling Technology, Danvers, MA, USA) and non-specific normal rabbit and mouse IgG (Santa Cruz Biotechnology) as the controls. The secondary antibodies were horseradish peroxidase-conjugated sheep anti-mouse IgG and donkey anti-rabbit IgG detected by enhanced chemiluminescence with reagents from GE Healthcare Bio-Sciences AB.

Enzymatic activity assays. PKC- $\delta$ activity was monitored according to a modified procedure described previously (60). Briefly, the reaction mixture $(100 \mu \mathrm{l})$ consisted of $100 \mu \mathrm{M}$ ATP with $\left[\gamma^{-}{ }^{32} \mathrm{P}\right]$ ATP $(5 \mu \mathrm{Ci}), 1 \mathrm{mM}$ DTT, $5 \mathrm{mM} \mathrm{MgCl}_{2}$, $25 \mathrm{mM}$ Tris- $\mathrm{HCl}(\mathrm{pH} 7.5), 0.5 \mathrm{mM}$ EGTA and $500 \mu \mathrm{M}$ of the PKC- $\delta$-specific peptide substrate, Ala-Arg-Arg-Lys-ArgLys-Gly-Ser-Phe-Phe-Gly-Gly. Reactions were initiated by the addition of lysosome-enriched extracts incubated at $30^{\circ} \mathrm{C}$ for $10 \mathrm{~min}$ and then stopped on ice. Reaction mixtures were spotted on PVDF membranes and washed 4-fold in $0.5 \mathrm{ml}$ of $1 \%$ phosphoric acid. ${ }^{32} \mathrm{P}$ incorporation was measured by liquid scintillation counting. In each experimental assay, negative control reactions lacking the substrate peptide were included. The results are expressed as CPM min-1 $\mathrm{mg}^{-1}$.

ASM activity was assayed according to the Hojjati and Jiang protocol (61) with colorimetric-based kits purchased from the Cayman Chemical Company (Ann Arbor, MI, USA). Briefly, in this assay, SM was hydrolyzed by ASM to $\mathrm{PCH}$ and CER. Alkaline phosphatase then generates choline from $\mathrm{PCH}$ and the newly-formed choline serves to generate hydrogen peroxide in a reaction catalyzed by choline oxidase. Finally, with peroxidase, hydrogen peroxide reacts with diamine oxidases and 4-aminoantipyrine to generate a blue color with an optimal absorption at $595 \mathrm{~nm}$. ASM activity was evaluated from highly-enriched lysosomal extracts in a reaction mixture containing excess SM $(150 \mu \mathrm{M})$. Enzymatic reactions were carried out at room temperature under constant agitation, and enzyme activity measured at 10-min intervals for $60 \mathrm{~min}$ at the optimal absorption of $595 \mathrm{~nm}$ with a microplate reader (Model 3550, Bio-Rad Laboratories, Hercules, CA, USA). Control reactions consisted of lyso- somal extracts incubated in the reaction buffer without SM or without protein extracts. The results are expressed as the optical density (OD; $595 \mathrm{~nm}$ ) $\mathrm{min}^{-1} \mathrm{mg}^{-1}$.

Lipid species analysis by electrospray ionization tandem mass spectrometry (ESI-MS/MS). Lipid analysis was performed by ESI-MS/MS as described previously $(62,63)$. Briefly, samples were quantified by direct flow injection analysis using a precursor ion scan of m/z 184 specific for phosphocholine-containing lipids, including phosphatidylcholine (PC), SM and LPC. Neutral loss scans of m/z 141 and m/z 185 were used for phosphatidylethanolamine (PE) and phosphatidylserine (PS), respectively. PE-based plasmalogens (PLASMs) were analyzed by fragment ions of $\mathrm{m} / \mathrm{z} 364,380$ and 382. Ammonium adduct ions of phosphatidylglycerol (PG) and phoshatidylinositol (PI) were analyzed by neutral loss scans of m/z 189 and 277, respectively (64). CER was analyzed similar to a previously described method (65) using $\mathrm{N}$-heptadecanoyl-sphingosine as the internal standard. Free cholesterol (FC) and cholesterol ester (CE) were quantified using a fragment ion of $\mathrm{m} / \mathrm{z} 369$ after selective derivatization of FC using acetyl chloride. The correction of isotopic overlap of lipid species as well as data analysis by self programmed Excel Macros, was performed for all lipid classes. Sphingoid bases, hexosyl- and lactosylceramides (LacCER) were quantified by hydrophilic interaction chromatography (HILIC) coupled with ESI-MS/MS in a similar way as described previously (66).

Statistical analysis. Mann-Whitney or Student's t-tests were performed between data points as indicated in the figure legends with GraphPad InStat software (v3.0b). P-values of $\leq 0.05$ were considered to be statistically significant.

\section{Results}

Lysosomal and mitochondrial pathways of apoptosis are quickly activated after CPT treatment in U-937 cells. Human histiocytic lymphoma U-937 cells are highly sensitive to DNA damage and rapidly die by apoptosis after treatment with the DNA topoisomerase I inhibitor CPT $(1 \mu \mathrm{M})(19,44-46)$. Manifestations of the onset of apoptosis in these cells are illustrated by the simultaneous activation of the mitochondrial and lysosomal pathways within 2 to $3 \mathrm{~h}$ after drug treatment, with $\downarrow \Delta \Psi \mathrm{m}$ (67) (Fig. 1A) and LLM (Fig. 1B) accompanied by lysosomal cathepsin $\mathrm{D}$ release into the cytosol (Fig. 1C). The cleavage of the executioner procaspase-3 into catalytic fragments of the active caspase (Fig. 1D) also indicates that apoptosis has been initiated. These events correspond to the activation phase of apoptosis, followed by the execution phase where the morphological features of apoptotic cells become clearly evident $4 \mathrm{~h}$ after CPT treatment (Fig. 1E).

$P K C-\delta$ is required for LLM in CPT-treated U-937 cells. Recently, taking a comparative proteomics approach on highly-enriched lysosomal extracts, we identified PKC- $\delta$ as a protein that rapidly translocates to lysosomes after CPT treatment in U-937 cells (46). The PKC- $\delta$ translocation to lysosomes after CPT treatment (Fig. 2A) correlated with the 
A)

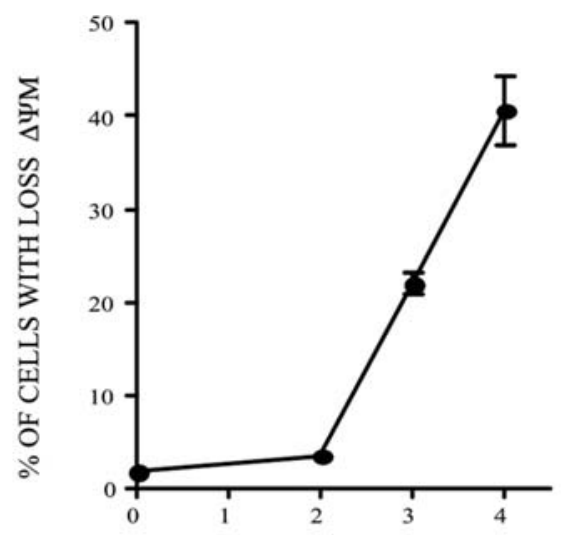

B)

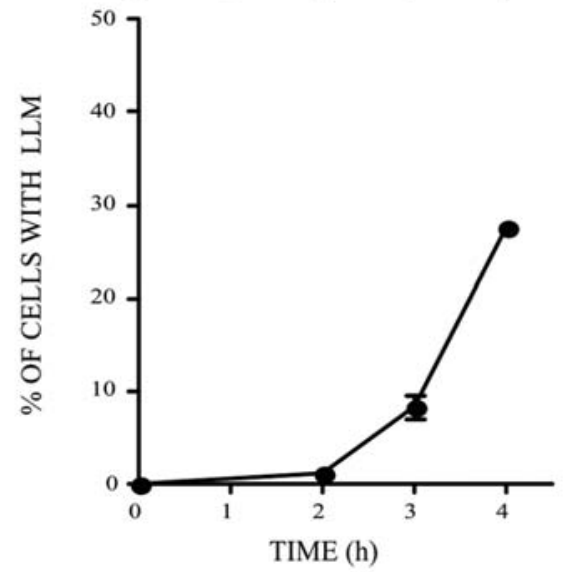

E)

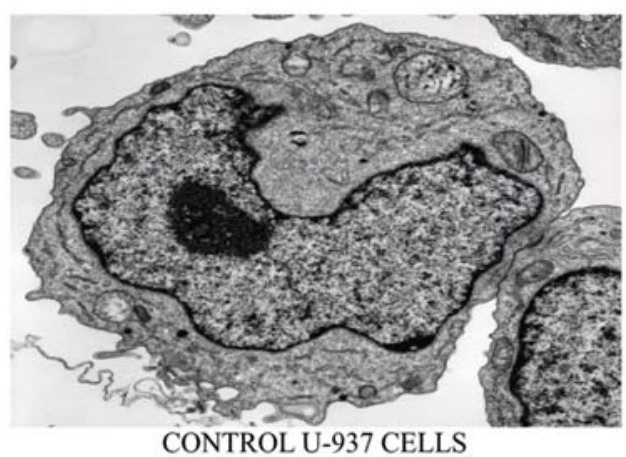

C)

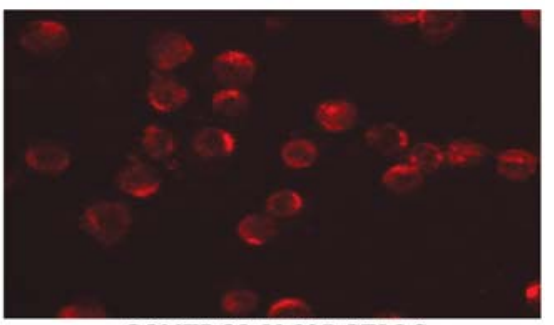

CONTROL U-937 CELLS

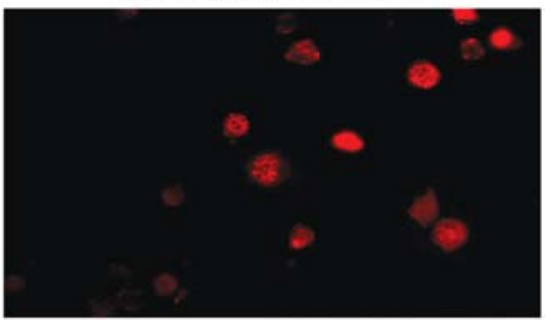

U-937 CELLS + CPT (3 h)

D)
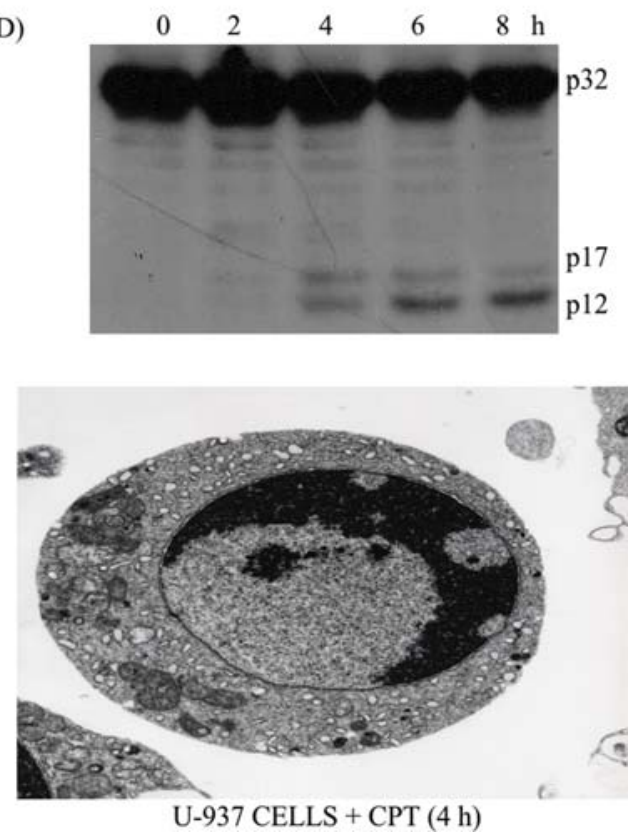

Figure 1. CPT-induced apoptosis in U-937 cells. (A) $\downarrow \Delta \Psi \mathrm{m}$ and (B) LLM were monitored in U-937 cells after CPT $(1 \mu \mathrm{M})$ treatment. Bars represent the means of 4 independent determinations and error bars represent SEM. (C) Control and CPT-treated U-937 cells were stained with a specific antibody against cathepsin D to monitor the de-localization of lysosomal cathepsin D, $3 \mathrm{~h}$ after CPT treatment $(1 \mu \mathrm{M})$. (D) Western blotting of caspase-3. The active cleaved 17 and $12 \mathrm{kDa}$ fragments of procaspase-3 $(32 \mathrm{kDa})$ are clearly visible $4 \mathrm{~h}$ after CPT treatment $(1 \mu \mathrm{M})$. (E) Electron microscopy representative of the control and CPT-treated U-937 cells (4 h).

increase in $\mathrm{PKC}-\delta$ activity in highly-enriched lysosomal extracts (Fig. 2B). The inhibition of PKC- $\delta$ activity with the pharmacological inhibitor, ROTT (68) (Fig. 2B), or the knock-down of PKC- $\delta$ expression with siRNA (56) (Fig. 2C) had a significant effect on CPT-induced LLM (Fig. 2D), revealing that PKC- $\delta$ plays a key role in LLM induction by CPT. The inhibition of PKC- $\delta$ activity and the subsequent reduction of LLM also had an effect on the kinetics of DNA fragmentation, a validated measure of apoptosis in CPTtreated U-937 cells (Fig. 2E). The purity of the lysosomal extracts has recenlty been documented in detail (46).

$P K C-\delta$ mediates ASM phosphorylation and activation in lysosomes after CPT treatment. It has been reported that
PKC $-\delta$ in lysosomes phosphorylates and activates ASM, a key enzyme that catalyzes the degradation of membranebound SM into PCH and CER $(54,55)$. In order to evaluate the effect of PKC- $\delta$ translocation and activity in lysosomes after CPT treatment, we first evaluated ASM expression in enriched lysosomal extracts after CPT treatment. CPT treatment did not alter the lysosomal ASM expression level (Fig. 3A). However, reciprocal IP experiments performed on these highly-enriched lysosomal extracts followed by Western blotting revealed that ASM phosphorylation increased significantly in lysosomes after CPT treatment (Fig. 3B). These experiments were conducted with specific antibodies recognizing specific PKC- $\delta$ Ser-phosphorylation consensus sequences and ASM (Fig. 3B). Co-treatment with ROTT 
A)

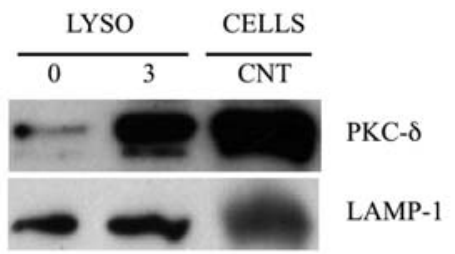

C)

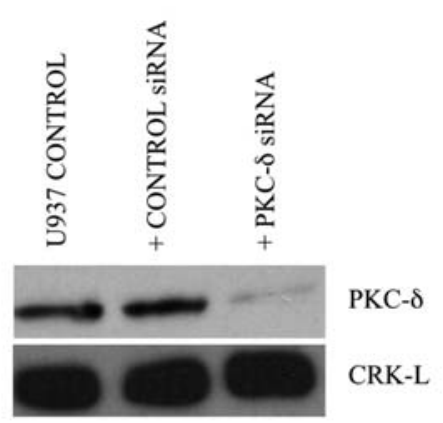

D)

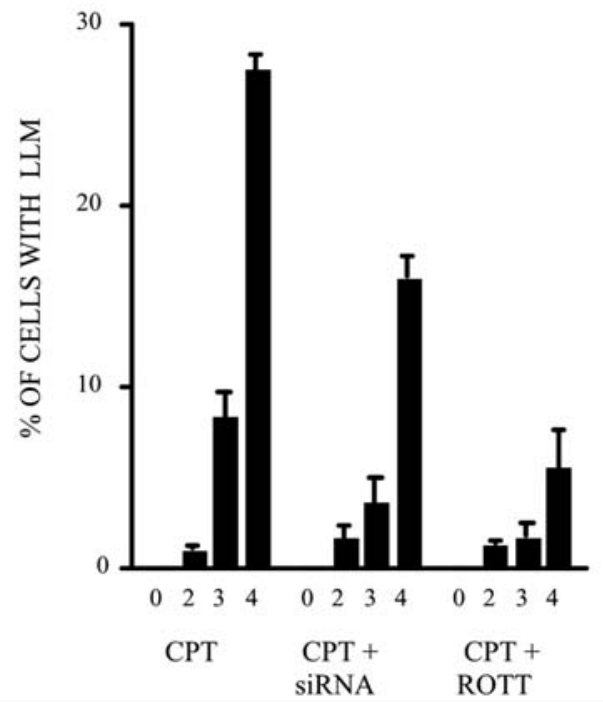

B)

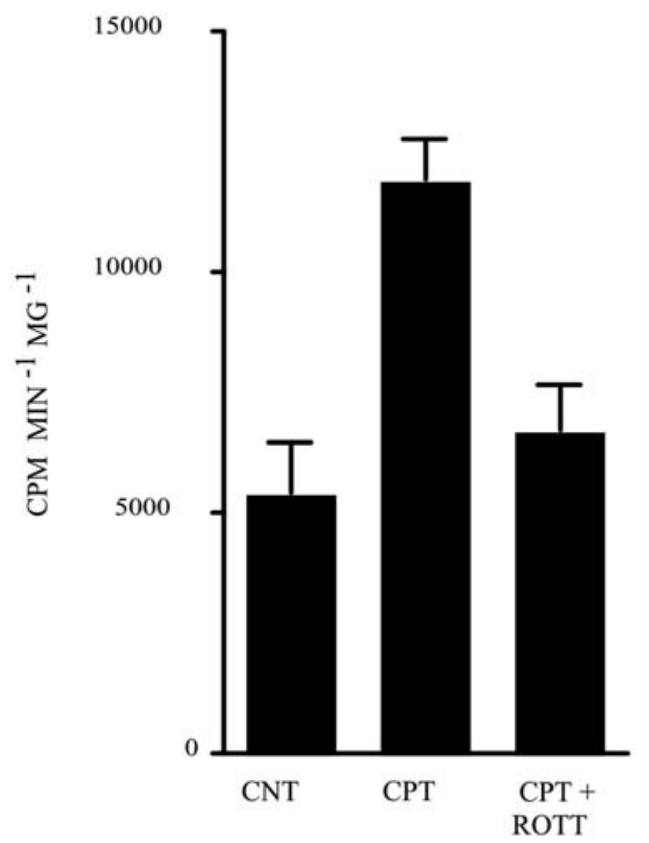

E)

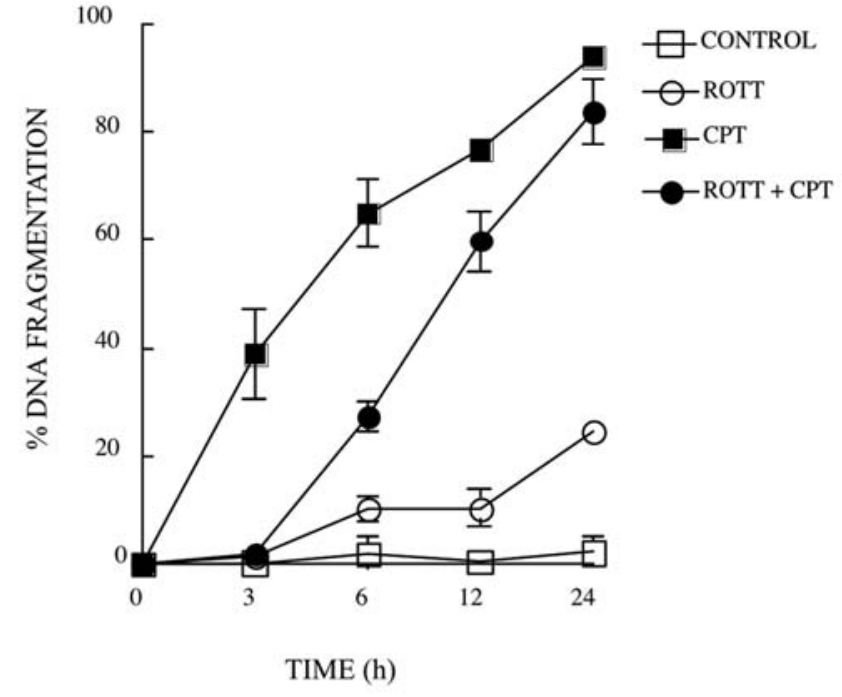

Figure 2. PKC- $\delta$ is required for LLM in CPT-treated U-937 cells. (A) Expression of PKC- $\delta(80 \mathrm{kDa})$ in highly-enriched lysosomal extracts from the control (CNT) and CPT-treated U-937 cells $(1 \mu \mathrm{M} ; 3 \mathrm{~h})$. Whole cell extract from the CNT cells is shown as the PKC- $\delta$ antibody control. LAMP-1 expression is the loading control. (B) PKC- $\delta$ activity monitored in highly-enriched lysosomal extracts from CNT and CPT-treated U-937 cells $(1 \mu \mathrm{M} ; 3 \mathrm{~h})$ in the absence and presence of the PKC- $\delta$ inhibitor, ROTT $(3.5 \mu \mathrm{M})$. Bars represent the means of 4 independent determinations and error bars represent SEM. (C) The knockdown of the expression of PKC- $\delta$ by siRNA experiment. CRK-L expression is the loading control. The average of PKC- $\delta$ silencing efficiency in 3 independent experiments was $47 \pm 16 \%$, based on densitometry analysis (data not shown). (D) LLM was monitored after CPT treatment (1 $\mu \mathrm{M})$ in U-937 cells where PKC- $\delta$ was silenced by siRNA or PKC- $\delta$ activity inhibited by ROTT $(3.5 \mu \mathrm{M})$. Bars represent the means of 3 independent determinations and error bars represent SEM. (E) The percentage of DNA fragmentation was monitored after CPT treatment $(1 \mu \mathrm{M})$ in the absence or presence of the PKC- $\delta$ inhibitor, ROTT (3.5 $\mu \mathrm{M})$. Data points represent the means of 3 duplicated independent determinations and error bars represent SEM.

reduced ASM phosphorylation (Fig. 3B). The increment of ASM phosphorylation in lysosomes after CPT treatment also correlated with the heightened ASM enzymatic activity (Fig. 3C). The inhibition of ASM activity by DESP (69) or the suppression of PKC- $\delta$ by ROTT reduced ASM enzymatic activity in lysosomes during CPT treatment (Fig. 3C). Finally, the inhibition of ASM activity by DESP also interfered with LLM (Fig. 3D). On the contrary, the inhibition of ceramide synthase (CS) by FB1 (70), a key enzyme involved in de novo CER generation, had no effect on LLM after CPT treatment
(Fig. 3D), confirming the importance of ASM activity for LLM.

PKC- $\delta$-mediated activation of lysosomal ASM leads to CER generation and accumulation in lysosomes. ASM activation results in the hydrolysis of SM into CER. In order to investigate whether the ASM activation mediated by PKC- $\delta$ after CPT treatment is associated with changes in lipid and sphingolipid distribution in lysosomes, highly-enriched lysosomal extracts were analyzed for their lipid composition 
A)

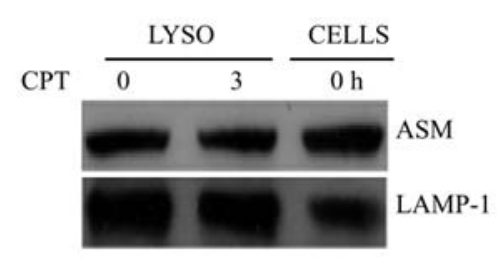

B)

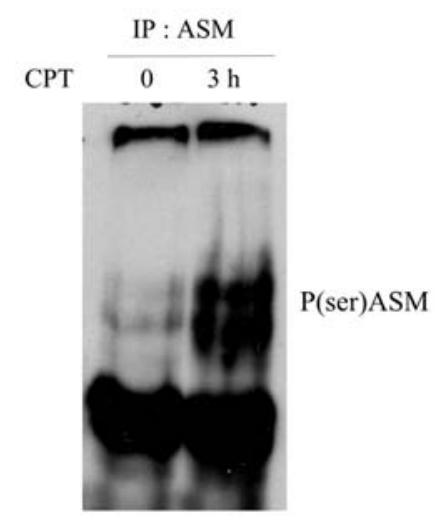

IP: Phos(Ser)-PKC substrate

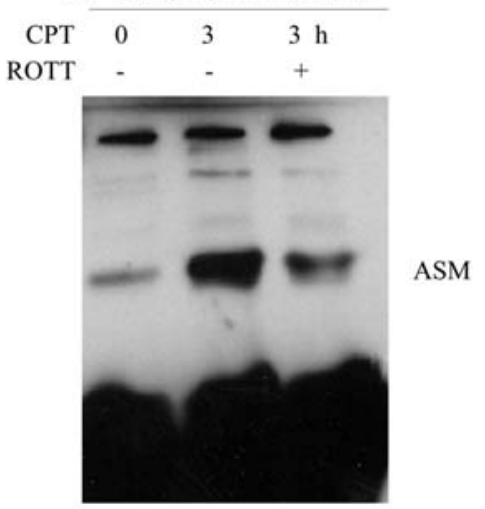

C)

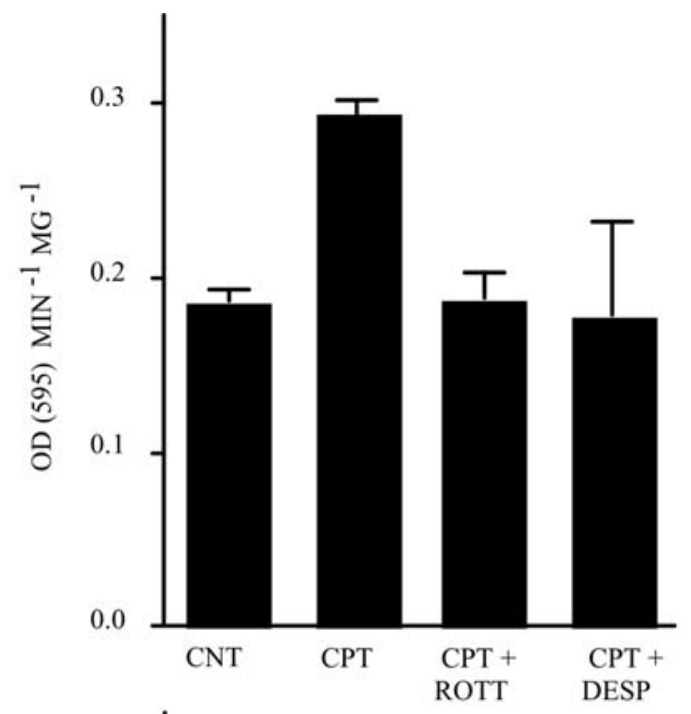

D)

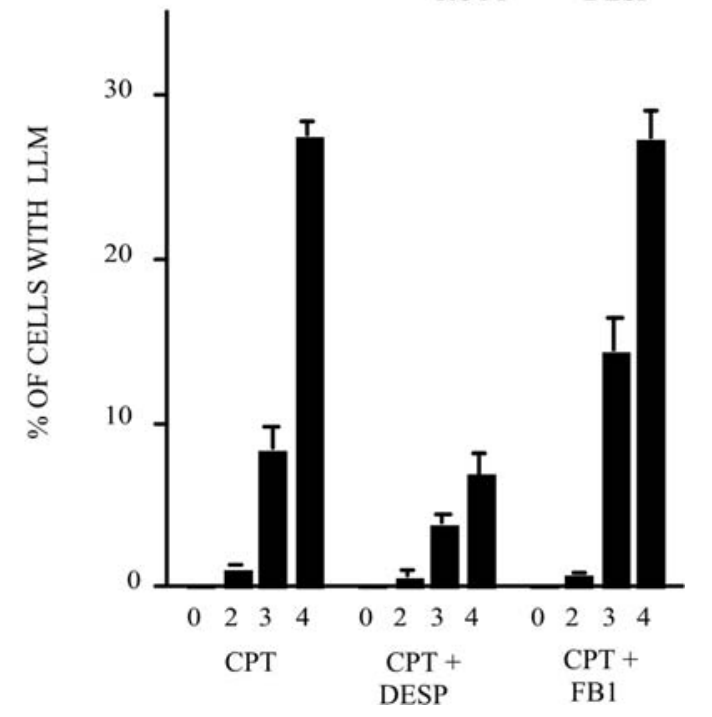

Figure 3. PKC- $\delta$ mediates ASM phosphorylation and activation in lysosomes after CPT treatment. (A) ASM expression in highly-enriched lysosomal extracts from the control (CNT) and CPT-treated U-937 cells $(1 \mu \mathrm{M} ; 3 \mathrm{~h})$. Whole-cell extract (CNT) is shown as the ASM antibody control. LAMP-1 expression is the loading control. (B) Western blotting revealed the ASM phosphorylation level after CPT-treatment ( $1 \mu \mathrm{M}$; $3 \mathrm{~h})$. IP was performed from highly-enriched lysosomal preparations. Upper panel, IP was undertaken with anti-ASM antibodies and Western blotting was carried out with anti-phospho-(Ser) PKC substrate antibodies. The doublet represents some protein degradation. Lower panel, reciprocal experiment where IP was performed with anti-phospho-(Ser) PKC substrate antibodies and Western blotting was performed with anti-ASM. (C) ASM activity monitored in highly-enriched lysosomal extracts from CNT and CPT-treated U-937 cells $(1 \mu \mathrm{M} ; 3 \mathrm{~h})$ in the absence and presence of the PKC- $\delta$ inhibitor, ROTT (3.5 $\mu \mathrm{M})$, and the ASM inhibitor, DESP (10 $\mu \mathrm{M})$. Bars represent the means of 3 independent determinations and error bars represent SEM. (D) LLM was monitored after CPT treament in U-937 cells where ASM activity was inhibited by DESP $(10 \mu \mathrm{M})$, and CS activity was inhibited by FB1 $(10 \mu \mathrm{M})$. Bars represent the means of 3 independent determinations and error bars represent SEM.

by ESI-MS/MS $(62,63)$. Lipid profiling analysis revealed that CER and LacCER significantly increased in lysosomes after CPT treatment (Fig. 4A). LPC increment was also observed, although it was not stastistically significant due to variation among samples (Fig. 4A). All of the other lipid species analyzed, including total SM, dihydro-sphingomyelin (dihSM), PE, PC, PLASM, PS, PG, PI, hexosylceramide (HexCER), SPH, sphinganine (SPA), CE and FC, did not change (Fig. 4A). The inhibition of PKC- $\delta$ by ROTT during CPT treatment impeded CER and LacCER accumulation in lysosomes but had no effect on LPC accumulation (Fig. 4B). Similarly, the inhibition of ASM by DESP reduced CER and LacCER accumulation induced by CPT treatment but had no effect on LPC increment (Fig. 4C). Finally, the inhibition of CS by FB1 did not alter CER accumulation in lysosomes after CPT treatment (Fig. 4D). The detailed quantitative distribution of CER (Fig. 5A) and SM (Fig. 5B) species generated in lysosomes after CPT treatment revealed a significant elevation in CER 16:0 (Fig. 5A). After an initial increment of SM 16:0 $2 \mathrm{~h}$ after CPT treatment (Fig. 5B), a reduction of SM 16:0 paralleled the increase in CER 16:0.

On the whole, these results indicate that after CPT treatment, PKC- $\delta$ rapidly translocates to lysosomes, where it phosphorylates and activates ASM, which leads to the CER accumulation and LLM.

\section{Discussion}

Great efforts have been invested in the past several years to understand the signaling pathways of caspase activation, a 

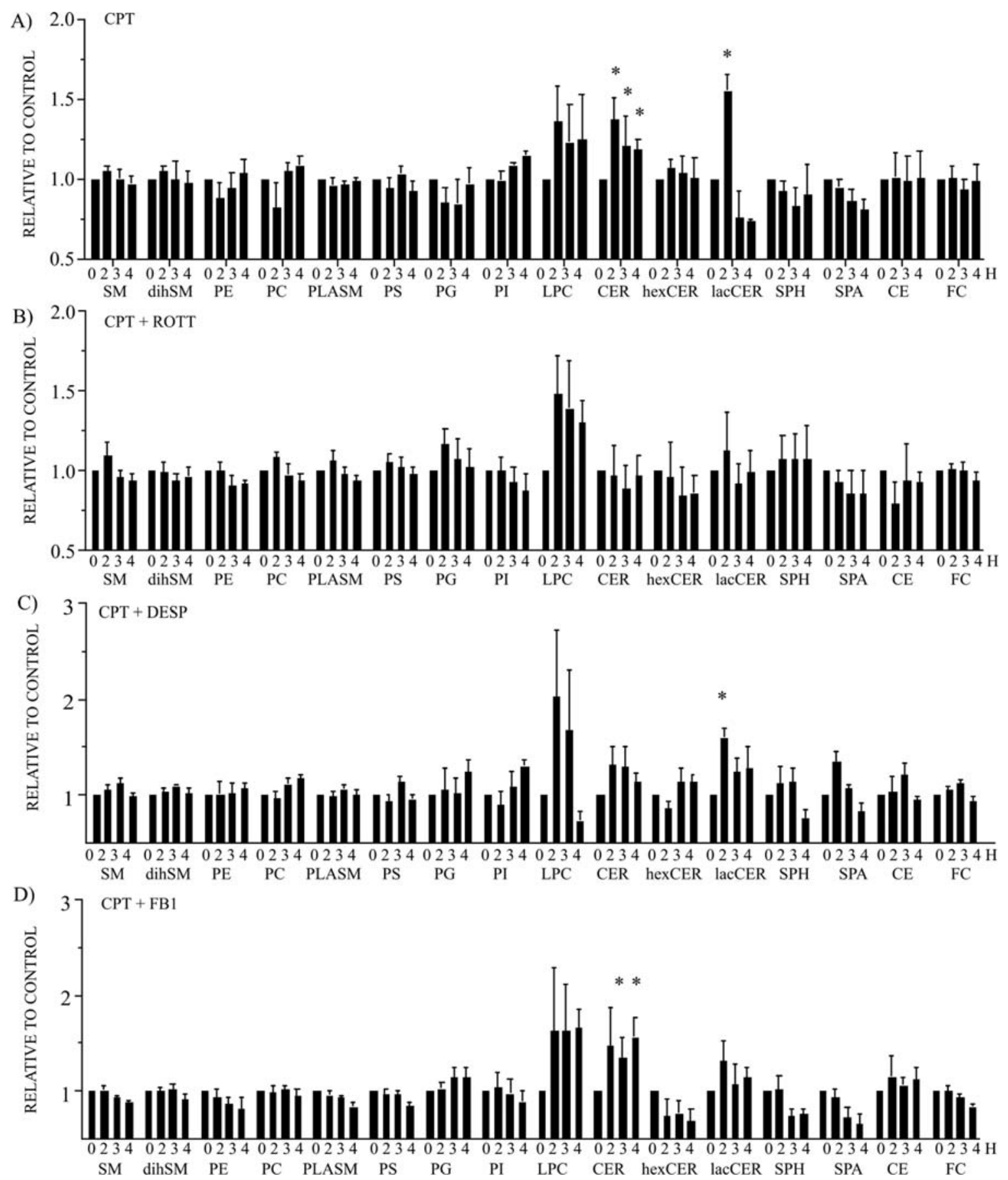

Figure 4. PKC- $\delta$-mediated activation of ASM leads to CER generation and accumulation in lysosomes. ESI-MS/MS lipid profiling of highly-enriched lysosomal extracts obtained from U-937 cells treated with (A) CPT (1 $\mu \mathrm{M})$, (B) CPT $(1 \mu \mathrm{M})$ in the presence of the PKC- $\delta$ inhibitor, ROTT (3.5 $\mu \mathrm{M})$, (C) CPT $(1 \mu \mathrm{M})$ in the presence of the ASM inhibitor, DESP $(10 \mu \mathrm{M})$, and (D) CPT $(1 \mu \mathrm{M})$ in the presence of the CS inhibitor, FB1 $(10 \mu \mathrm{M})$. Bars represent the means of 4 independent determinations and error bars represent SEM. The data are presented as relative to the untreated control cells. "Significant differences between treated cells in comparision to the control cells.

crucial step for apoptosis induction. The most studied molecular mechanisms of caspase activation and apoptosis, the mitochondrial and cell death receptor pathways, are well characterized. However, alternative and amplification pathways of caspase activation are much less known, including the lysosomal pathway of apoptosis. The aim of this study was to investigate the role of PKC- $\delta$ in the induction of LLM during the early stages of CPT-induced apoptosis. Previously, we reported that $\mathrm{PKC}-\delta$ rapidly translocates to lysosomes after CPT treatment in human histiocytic lymphoma U-937 cells (46). In this study, we show that PKC- $\delta$ regulates LLM via the phosphorylation and activation of lysosomal ASM, which leads to CER generation and accumulation in lysosomes after CPT.

PKC- $\delta$ has been reported to participate in the apoptotic process in diverse cell types with a plethora of stimuli (49-51). The observations reported in this study correspond to the induction phase of apoptosis, in contrast to the execution 


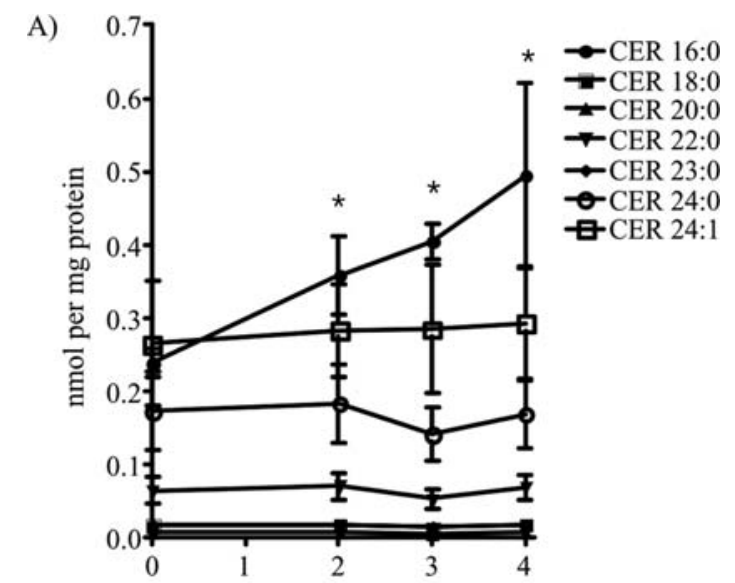

B)

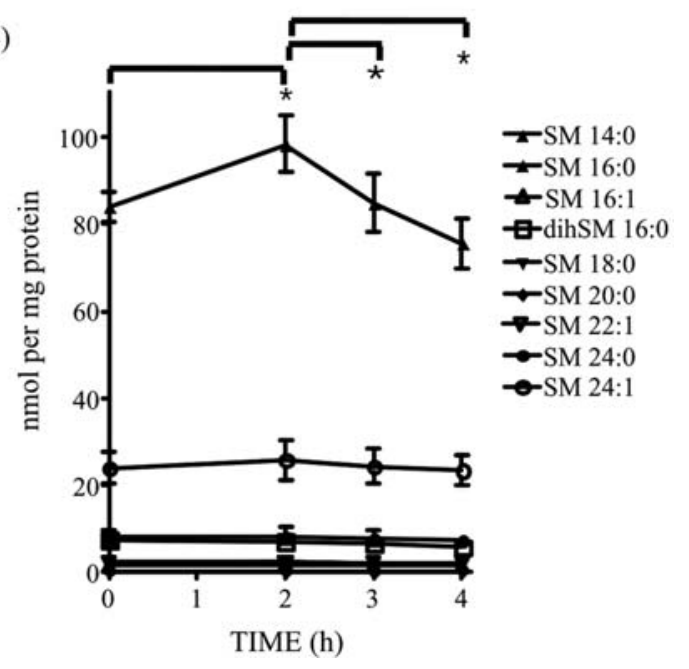

Figure 5. Quantitative distribution of CER and SM species generated in lysosomes after CPT treatment. (A) CER and (B) SM species were analyzed by ESI-MS/MS. Data points represent the means of 4 independent determinations and error bars represent SEM. *Significant differences between treated cells versus the control cells or between data points as indicated.

phase where active caspases fire numerous substrates, including $\mathrm{PKC}-\delta$. PKC- $\delta$ activity and re-localization during apoptosis are regulated via threonine residue phosphorylation, or after cleavage of its regulatory domain mediated by caspase-3 (71). The latter mode of activation is unlikely to play a role in our model as PKC- $\delta$ cleavage is not apparent during the early stages of CPT-induced apoptosis (46). In agreement with our observations, other studies have reported that PKC- $\delta$ cleavage occurs only $24 \mathrm{~h}$ after NSC606985 treatment, a CPT analog, in U-937 cells (72).

PKC- $\delta$ pro-apoptotic functions are mediated through various targeted proteins. So far, the apoptotic functions of PKC- $\delta$ have been associated with its cytosolic and nuclear localization and activation of multiple signaling proteins, including JNK, p38MAPK, ATM, PKB/AKT, cAbl, p73, DNA-PK, lamin and scramblase (49-53). PKC- $\delta$, upon phorbol 12-myristate 13-acetate treatment, has been shown to rapidly translocate to lysosomes where it phosphorylates and activates ASM, a key enzyme that catalyzes the degradation of membrane-bound SM into PCH and CER (54). After UV treatment, ASM has also been reported to be phosphorylated on Ser508 by PKC- $\delta$ in MCF-7 breast cancer cells, triggering cytosolic CER accumulation and provoking mitochondrial fragmentation and cytochrome c release (55).

CER generation has often been associated with apoptosis following a variety of insults in many studies (73). CER accumulates in cells quickly but transiently (55), or progressively and continuously (74) after apoptosis-inducing treatment. While most of the attention has generally been focused on total cellular CER content, and the mediated effects on plasma membranes or mitochondria $(55,74)$, lipid and sphingolipid analyses in this study were performed on highly-enriched lysosomal extracts after CPT treatment and the consequences of lysosomal CER accumulation were associated with LLM. Our experiments revealed that in addition to the PKC- $\delta$ / ASM/CER pathway that regulates mitochondrial responses

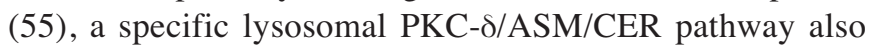
regulates early lysosomal responses after CPT treament. It is unlikely that the increased lysosomal CER content observed in this study could also act on the mitochondria, as it has been previously shown that lysosomal CER cannot exit into the cytosol unless it is deacylated to SPH (75).

In the present study, we also observed an increase in LPC content in lysosomes after CPT treatment, although this variation was statistically not significant. The lysosomal accumulation of LPC, a PLA 2 -produced lipid metabolite, has been reported to provoke lysosomal rupture. It is believed that LPC, in concert with cytosolic PLA $\mathrm{A}_{2}$ and cytosolic PLC, osmotically destabilizes lysosomal membranes via a $\mathrm{K}(+) /$ $\mathrm{H}(+)$ exchange process $(33,37-40)$. Our study suggests that the apparent LPC accumulation is independent of PKC- $\delta$ after CPT, and that CER accumulation is required for the destabilization of the lysosomal membranes, even in the presence of high LPC levels. It is conceivable that CER and LPC cooperate for dynamic modifications of lysosomal membranes to activate the $\mathrm{K}(+) / \mathrm{H}(+)$ exchange process associated with LLM, or to form novel channels inside lysosomal membranes. Indeed, it has been reported that CER can form channels inside lipid membranes, allowing the passage of molecules with a size of up to $60 \mathrm{kDa}(76)$. Considering that most lysosomal cathepsins are $<60 \mathrm{kDa}$, such CER-formed channels could be implicated not only in LLM after CER accumulation at lysosome membranes but also in cathepsin release into the cytosol. Of interest, it has been reported that CER could interact with cathepsin D leading to its auto-activation (17). Finally, CER is generally generated in cells from SM hydrolysis mediated by ASM or from the de novo synthesis of CER mediated by CS (77). As both enzymes are found in lysosomes $(78,79)$, we also used pharmacological inhibitors targeting both ASM and CS in this study, to confirm that ASM is the major source of CER generation in lysosomes after CPT treatment. The detailed analysis of CER and SM species generated in lysosomes after CPT treatment indicating that the SM 16:0 reduction paralleled the CER 16:0 elevation, also confirmed the key role of ASM for CER generation after CPT treatment.

Accumulating evidence suggests that different intracellular organelles contribute together to amplify apoptosis initiation. After CPT treatment, both the mitochondrial and lysosomal pathways are engaged concomitantly, indicating the cooperation between the two pathways to activate a variety of killer proteases, mainly caspases and cathepsins. 
PKC- $\delta$ inhibition reduced LLM (but also $\downarrow \Delta \Psi \mathrm{m}$; data not shown) and delayed apoptosis, suggesting that the lysosomal PKC- $\delta / A S M / C E R$ pathway revealed in our study contributes, at least in part, to the activation of CPT-induced apoptosis. Due to all the pleotropic effects of PKC- $\delta$ in signaling apoptosis, it is difficult to accurately quantitate or assess the importance of the lysosomal pathway. Indeed, we have reported previously that blocking caspase activity in these cells after CPT treatment prevents the typical manifestation of apoptosis, with cells dying by necrosis (80). Blocking cathepsin B activity after CPT treatment will only slightly interfere with the kinetics and amplitude of apoptosis, while blocking the mitochondrial pathway of apoptosis either with mitochondrial permeabilization inhibitors or Bcl-xL overexpression has a more pronounced effect on the kinetics of apoptosis (19). Therefore, the mitochondrial pathway of apoptosis is predominant in these cells after CPT treatment, while the lysosomal pathway acts to amplify cell death signals.

A few compounds that induce significant cell death by triggering LLM and cathepsin-mediated killing of tumor cells have been identified. Boya et al reported that widelyadministered quinolone antibiotics, including ciprofloxacin and norfloxacin, mediate LLM, cathepsin release and apoptosis, either alone or in combination with UV irradiation (23). Similarly, cytotoxin 3-aminopropanal (81) and siramesine (82) specifically target the lysosomal compartment to induce LLM and apoptosis. The screening of a small molecule library identified new compounds that induce significant LLM and cathepsin-mediated cell death in tumor cell lines (83). Combination of DNA-damaging agents with the quinolone class of antibiotics enables lower doses of DNAdamaging agents to be used with the same apoptotic capacity when combined together (84). Thus, the potential of activating the lysosomal death pathway is promising and under development for novel cancer therapeutic approaches (85).

\section{References}

1. Ferri KF and Kroemer G: Organelle-specific initiation of cell death pathways. Nat Cell Biol 3: E255-E263, 2001.

2. Antunes F, Cadenas E and Brunk UT: Apoptosis induced by exposure to a low steady-state concentration of $\mathrm{H}_{2} \mathrm{O}_{2}$ is a consequence of lysosomal rupture. Biochem J 356: 459-555, 2001.

3. Roberg K and Ollinger K: Oxidative stress causes relocation of the lysosomal enzyme cathepsin D with ensuing apoptosis in neonatal rat cardiomyocytes. Am J Pathol 152: 1151-1156, 1998.

4. Dare E, Li W, Zhivotovsky B, Yuan X and Ceccatelli S: Methylmercury and $\mathrm{H}_{2} \mathrm{O}_{2}$ provoke lysosomal damage in human astrocytoma D384 cells followed by apoptosis. Free Radic Biol Med 30: 1347-1356, 2001.

5. Brunk UT: Lysosomotropic detergents induce time- and dosedependent apoptosis/necrosis in cultured cells. Redox Rep 5: $87-88,2000$

6. Uchimoto T, Nohara H, Kamehara R, Iwamura M, Watanabe N and Kobayashi Y: Mechanism of apoptosis induced by a lysosomotropic agent, L-Leucyl-L-Leucine methyl ester. Apoptosis 4: 357-362, 1999.

7. Li W, Yuan X, Nordgren G, Dalen H, Dubowchik GM, Firestone RA and Brunk UT: Induction of cell death by the lysosomotropic detergent MSDH. FEBS Lett 470: 35-39, 2000.

8. Van Nierop K, Muller FJ, Stap J, van Noorden CJ, van Eijk M and de Groot C: Lysosomal destabilization contributes to apoptosis of germinal center B-lymphocytes. J Histochem Cytochem 54: 1425-1435, 2006.
9. Brunk UT, Dalen H, Roberg K and Hellquist HB: Photooxidative disruption of lysosomal membranes causes apoptosis of cultured human fibroblasts. Free Radic Biol Med 23: 616-626, 1997.

10. Kessel D, Luo Y, Mathieu P and Reiners JJJ: Determinants of the apoptotic response to lysosomal photodamage. Photochem Photobiol 71: 196-200, 2000

11. Nagata S, Obana A, Gohto Y and Nakajima S: Necrotic and apoptotic cell death of human malignant melanoma cells following photodynamic therapy using an amphiphilic photosensitizer, ATX-S10(Na). Lasers Surg Med 33: 64-70, 2003.

12. Ichinose $S$, Usuda J, Hirata $T$, Inoue $T$, Ohtani $K$, Maehara $S$, Kubota M, Imai K, Tsunoda Y, Kuroiwa Y, Yamada K, Tsutsui H, Furukawa K, Okunaka T, Oleinick NL and Kato H: Lysosomal cathepsin initiates apoptosis, which is regulated by photodamage to Bcl-2 at mitochondria in photodynamic therapy using a novel photosensitizer, ATX-s10 (Na). Int J Oncol 29: 349-355, 2006.

13. Brunk UT and Svensson I: Oxidative stress, growth factor starvation and Fas activation may all cause apoptosis through lysosomal leak. Redox Rep 4: 3-11, 1999.

14. Guicciardi ME, Deussing J, Miyoshi H, Bronk SF, Svingen PA, Peters C, Kaufmann SH and Gores GJ: Cathepsin B contributes to TNF-alpha-mediated hepatocyte apoptosis by promoting mitochondrial release of cytochrome c. J Clin Invest 106: 1127-1137, 2000.

15. Gyrd-Hansen M, Farkas T, Fehrenbacher N, Bastholm L, Hoyer-Hansen M, Elling F, Wallach D, Flavell R, Kroemer G, Nylandsted J and Jäättela M: Apoptosome-independent activation of the lysosomal cell death pathway by caspase-9. Mol Cell Biol 26: 7880-7891, 2006.

16. Kågedal K, Zhao M, Svensson I and Brunk UT: Sphingosineinduced apoptosis is dependent on lysosomal proteases. Biochem J 359: 335-343, 2001.

17. Heinrich M, Wickel M, Schneider-Brachert W, Sandberg C, Gahr J, Schwandner R, Weber T, Saftig P, Peters C, Brunner J, Krönke $M$ and Schütze $S$ : Cathepsin $D$ targeted by acid sphingomyelinase-derived ceramide. EMBO J 18: 5252-5263, 1999.

18. Paris C, Bertoglio J and Bréard J: Lysosomal and mitochondrial pathways in miltefosine-induced apoptosis in U937 cells. Apoptosis 12: 1257-1267, 2007.

19. Paquet C, Sané AT, Beauchemin M and Bertrand R: Caspaseand mitochondrial dysfunction-dependent mechanisms of lysosomal leakage and cathepsin B activation in DNA damageinduced apoptosis. Leukemia 19: 784-791, 2005.

20. Hishita T, Tada-Oikawa T, Tohyama K, Miura Y, Nishihara T, Tohyama Y, Yoshida Y, Uchiyama T and Kawanishi S: Caspase-3 activation by lysosomal enzymes in cytochrome cindependent apoptosis in myelodysplastic syndrome-derived cell line P39. Cancer Res 61: 2878-2884, 2001.

21. Broker LE, Huisman C, Span SW, Rodriguez JA, Kruyt FA and Giaccone G: Cathepsin B mediates caspase-independent cell death induced by microtubule stabilizing agents in non-small cell lung cancer cells. Cancer Res 64: 27-30, 2004.

22. Groth-Pedersen L, Ostenfeld MS, Hoyer-Hansen M, Nylandsted J and Jäättela M: Vincristine induces dramatic lysosomal changes and sensitizes cancer cells to lysosome-destabilizing siramesine. Cancer Res 67: 2217-2225, 2007.

23. Boya P, Andreau K, Poncet D, Zamzami N, Perfettini JL, Metivier D, Ojcius DM, Jäättela M and Kroemer G: Lysosomal membrane permeabilization induces cell death in a mitochondriondependent fashion. J Exp Med 197: 1323-1334, 2003.

24. Zang Y, Beard RL, Chandraratna RA and Kang JX: Evidence of a lysosomal pathway for apoptosis induced by the synthetic retinoid CD437 in human leukemia HL-60 cells. Cell Death Differ 8: 477-485, 2001.

25. Yu H, Zhou Y, Lind SE and Ding WQ: Clioquinol targets zinc to lysosomes in human cancer cells. Biochem J 417: 133-139, 2009.

26. Thibodeau MS, Giardina C, Knecht DA, Helble J and Hubbard AK: Silica-induced apoptosis in mouse alveolar macrophages is initiated by lysosomal enzyme activity. Toxicol Sci 80: 34-48, 2004.

27. Brunk UT, Neuzil J and Eaton JW: Lysosomal involvement in apoptosis. Redox Rep 6: 91-97, 2001

28. Turk B, Stoka V, Rozman-Pungercar J, Cirman T, DrogaMazovec G, Oreic K and Turk V: Apoptotic pathways: involvement of lysosomal proteases. Biol Chem 383: 1035-1044, 2002.

29. Guicciardi ME, Leist M and Gores GJ: Lysosomes in cell death. Oncogene 23: 2881-2890, 2004. 
30. Leist M and Jäättela M: Triggering of apoptosis by cathepsins. Cell Death Differ 8: 324-326, 2001.

31. Terman A, Kurz T, Gustafsson B and Brunk UT: Lysosomal labilization. IUBMB Life 58: 531-539, 2006.

32. Siskind LJ, Fluss S, Bui M and Colombini M: Sphingosine forms channels in membranes that differ greatly from those formed by ceramide. J Bioenerg Biomembr 37: 227-236, 2005

33. Hu JS, Li YB, Wang JW, Sun L and Zhang GJ: Mechanism of lysophosphatidylcholine-induced lysosome destabilization. J Membr Biol 215: 27-35, 2007.

34. Kågedal K, Johansson AC, Johansson U, Heimlich G, Roberg K, Wang NS, Jurgensmeier JM and Ollinger K: Lysosomal membrane permeabilization during apoptosis-involvement of Bax? Int J Exp Pathol 86: 309-321, 2005.

35. Zhao M, Brunk UT and Eaton JW: Delayed oxidant-induced cell death involves activation of phospholipase A2. FEBS Lett 509: 399-404, 2001

36. Mukherjee AK, Ghosal SK and Maity CR: Lysosomal membrane stabilization by a tocopherol against the damaging action of Vipera russelli venom phospholipase $\mathrm{A}_{2}$. Cell Mol Life Sci 53: 152-155, 1997.

37. Hiraoka M, Abe A, Lu Y, Yang K, Han X, Gross RW and Shayman JA: Lysosomal phospholipase A2 and phospholipidosis. Mol Cell Biol 26: 6139-6148, 2006.

38. Wang JW, Sun L, Hu JS, Li YB and Zhang GJ: Effects of phospholipase A2 on the lysosomal ion permeability and osmotic sensitivity. Chem Phys Lipids 144: 117-126, 2006.

39. Wang X, Wang LL and Zhang GJ: Guanosine 5'-[gammathio]triphosphate-mediated activation of cytosol phospholipase C caused lysosomal destabilization. J Membr Biol 211: 55-63, 2006

40. Zhao HF, Wang $X$ and Zhang GJ: Lysosome destabilization by cytosolic extracts, putative involvement of $\mathrm{Ca}(2+) /$ phospholipase C. FEBS Lett 579: 1551-1556, 2005.

41. Li N, Zheng Y, Chen W, Wang C, Liu X, He W, Xu H and Cao X: Adaptor protein LAPF recruits phosphorylated p53 to lysosomes and triggers lysosomal destabilization in apoptosis. Cancer Res 67: 11176-11185, 2007.

42. Nylandsted J, Gyrd-Hansen M, Danielewicz A, Fehrenbacher N Lademann U, Hoyer-Hansen M, Weber E, Multhoff G, Rohde M and Jäättela M: Heat shock protein 70 promotes cell survival by inhibiting lysosomal membrane permeabilization. J Exp Med 200: 425-435, 2004

43. Zhao M, Eaton JW and Brunk UT: Bcl-2 phosphorylation is required for inhibition of oxidative stress-induced lysosomal leak and ensuing apoptosis. FEBS Lett 509: 405-412, 2001.

44. Schmitt E, Cimoli G, Steyaert A and Bertrand R: Bcl-xL modulates apoptosis induced by anticancer drugs and delays DEVDase and DNA fragmentation-promoting activities. Exp Cell Res 240: 107-121, 1998.

45. Sané AT and Bertrand R: Distinct steps in DNA fragmentation pathway during camptothecin-induced apoptosis involved caspase-, benzyloxycarbonyl- and N-tosyl-L-phenylalanylchloromethyl ketone-sensitive activities. Cancer Res 58: 3066-3072, 1998.

46. Parent N, Winstall E, Beauchemin M, Paquet C, Poirier GG and Bertrand R: Proteomic analysis of enriched lysosomes at early phase of camptothecin-induced apoptosis in human U-937 cells. J Proteomics 72: 960-973, 2009.

47. Fukumoto S, Nishizawa Y, Hosoi M, Koyama H, Yamakawa K, Ohno S and Morii H: Protein kinase Cd inhibits the proliferation of vascular smooth muscle cells by suppressing G1 cyclin expression. J Biol Chem 272: 13816-13822, 1997.

48. Oh YT, Chun KH, Oh JI, Park JA, Kim YU and Lee SK: PKC- $\delta$ modulates p21WAF1/CIP1 ability to bind to Cdk2 during TNF alpha-induced apoptosis. Biochem Biophys Res Commun 339: 1138-1149, 2006.

49. Brodie $C$ and Blumberg PM: Regulation of cell apoptosis by protein kinase $\mathrm{c} \delta$. Apoptosis 8: 19-27, 2003.

50. Reyland ME: Protein kinase C $\delta$ and apoptosis. Biochem Soc Trans 35: 1001-1004, 2007

51. Reyland ME: Protein kinase $\mathrm{C}$ isoforms: multi-functional regulators of cell life and death. Front Biosci 14: 2386-2399, 2009.

52. Yoshida K: PKC delta signaling: mechanisms of DNA damage response and apoptosis. Cell Signal 19: 892-901, 2007.

53. Gomel R, Xiang C, Finniss S, Lee HK, Lu W, Okhrimenko H and Brodie C: The localization of protein kinase C-delta in different subcellular sites affects its proapoptotic and antiapoptotic functions and the activation of distinct downstream signaling pathways. Mol Cancer Res 5: 627-639, 2007.
54. Zeidan YH and Hannun YA: Activation of acid sphingomyelinase by protein kinase $\mathrm{C}$ delta-mediated phosphorylation. J Biol Chem 282: 11549-11561, 2007.

55. Zeidan YH, Wu BX, Jenkins RW, Obeid LM and Hannun YA A novel role for protein kinase $\mathrm{C}$ delta-mediated phosphorylation of acid sphingomyelinase in UV light-induced mitochondrial injury. FASEB J 22: 183-193, 2008.

56. Torgersen ML, Walchli S, Grimmer S, Skanland SS and Sandvig K: Protein kinase $\mathrm{C}$ delta is activated by Shiga toxin and regulates its transport. J Biol Chem 282: 16317-16328, 2007.

57. Labeed FH, Coley HM and Hughes MP: Differences in the biophysical properties of membrane and cytoplasm of apoptotic cells revealed using dielectrophoresis. Biochim Biophys Acta 1760: 922-929, 2006

58. Bertrand R, Sarang M, Jenkin J, Kerrigan D and Pommier Y: Differential induction of secondary DNA fragmentation by topoisomerase II inhibitors in human tumor cell lines with amplified c-myc expression. Cancer Res 51: 6280-6285, 1991.

59. Storrie B and Madden EA: Isolation of subcellular organelles. Methods Enzymol 182: 203-225, 1990.

60. Nishikawa K, Toker A, Johannes FJ, Songyang Z and Cantley LC: Determination of the specific substrate sequence motifs of protein kinase C isozymes. J Biol Chem 272: 952-960, 1997.

61. Hojjati WR and Jiang XC: Rapid, specific, and sensitive measurements of plasma sphingomyelin and phosphatidylcholine. J Lipid Res 47: 673-676, 2006.

62. Binder M, Liebisch G, Langmann T and Schmitz G: Metabolic profiling of glycerophospholipid synthesis in fibroblasts loaded with free cholesterol and modified low density lipoproteins. J Biol Chem 281: 21869-21877, 2006.

63. Wiesner P, Leidl K, Boettcher A, Schmitz G and Liebisch G: Lipid profiling of FPLC-separated lipoprotein fractions by electrospray ionization tandem mass spectrometry. J Lipid Res 50: 574-585, 2009.

64. Matyash V, Liebisch G, Kurzchalia TV, Shevchenko A and Schwudke D: Lipid extraction by methyl-tert-butyl ether for high-throughput lipidomics. J Lipid Res 49: 1137-1146, 2008.

65. Liebisch G, Drobnik W, Reil M, Trumbach B, Arnecke R, Olgemoller B, Roscher A and Schmitz G: Quantitative measurement of different ceramide species from crude cellular extracts by electrospray ionization tandem mass spectrometry (ESI-MS/MS). J Lipid Res 40: 1539-1546, 1999.

66. Scherer M, Schmitz G and Liebisch G: High-throughput analysis of sphingosine 1-phosphate, sphinganine 1-phosphate, and lysophosphatidic acid in plasma samples by liquid chromatography-tandem mass spectrometry. Clin Chem 55: 1218-1222, 2009.

67. Goldstein JC, Waterhouse NJ, Juin P, Evan GI and Green DR: The coordinate release of cytochrome $\mathrm{c}$ during apoptosis is rapid, complete and kinetically invariant. Nat Cell Biol 2: 156-162, 2000.

68. Gschwendt M, Müller HJ, Kielbassa K, Zang R, Kittstein W, Rincke $\mathrm{G}$ and Marks F: Rottlerin, a novel protein kinase inhibitor. Biochem Biophys Res Commun 199: 93-98, 1994.

69. Albouz S, Le Saux F, Wenger D, Hauw JJ and Baumann N: Modifications of sphingomyelin and phosphatidylcholine metabolism by tricyclic antidepressants and phenothiazines. Life Science 38: 357-363, 1986.

70. Merrill AH, van Echten G, Wang E and Sandhoff K: Fumonisin $\mathrm{B} 1$ inhibits sphingosine (sphinganine) N-acyltransferase and de novo sphingolipid biosynthesis in cultured neurons in situ. J Biol Chem 268: 27299-27306, 1993.

71. Khwaja A and Tatton L: Caspase-mediated proteolysis and activation of protein kinase $\mathrm{C}$ delta plays a central role in neutrophil apoptosis. Blood 94: 291-301, 1999.

72. Song MG, Gao SM, Du KM, Xu M, Yu Y, Zhou YH, Wang Q, Chen Z, Zhu YS and Chen GQ: Nanomolar concentration of NSC606985, a camptothecin analog, induces leukemic-cell apoptosis through protein kinase $\mathrm{C}$ delta-dependent mechanisms. Blood 105: 3714-3721, 2005.

73. Pettus BJ, Chalfant CE and Hannun YA: Ceramide in apoptosis: an overview and current perspectives. Biochim Biophys Acta 1585: $114-125,2002$.

74. Thomas HE, Darwiche R, Corbett JA and Kay TW: Evidence that beta cell death in the nonobese diabetic mouse is Fas independent. J Immunol 163: 1562-1569, 1999.

75. Chatelut M, Leruth M, Harzer K, Daga A, Marchesini S, Gatt S, Salvayre R, Courtoy P and Levade T: Natural ceramide is unable to escape the lysosome, in contrast to a fuorescent analogue. FEBS Lett 426: 102-106, 1998. 
76. Siskind LJ, Kolesnick RN and Colombini M: Ceramide channels increase the permeability of the mitochondrial outer membrane to small proteins. J Biol Chem 277: 26796-26803, 2002.

77. Ogretmen B and Hannun YA: Biologically active sphingolipids in cancer pathogenesis and treatment. Nat Rev Cancer 4: 604-616, 2004.

78. Stoffel W: Functional analysis of acid and neutral sphingomyelinases in vitro and in vivo. Chem Phys Lipids 102: 107-121, 1999.

79. He X, Okino N, Dhami R, Dagan A, Gatt S, Schulze H, Sandhoff $\mathrm{K}$ and Schuchman EH: Purification and characterization of recombinant human acid ceramidase. J Biol Chem 278: 32978-32986, 2003.

80. Sané AT and Bertrand R: Caspase inhibition in camptothecintreated U-937 cells is coupled with a shift from apoptosis to transient G1 arrest followed by necrotic cell death. Cancer Res 59: 3565-3569, 1999.
81. Li W, Yuan X, Ivanov S, Tracey KJ, Eaton JW and Brunk UT: 3-Aminopropanal, formed during cerebral ischaemia, is a potent lysosomotropic neurotoxin. Biochem J 371: 429-436, 2003.

82. Ostenfeld MS, Fehrenbacher N, Hoyer-Hansen M, Thomsen C, Farkas T and Jaattela M: Effective tumor cell death by $\sigma-2$ receptor ligand siramesine involves lysosomal leakage and oxidative stress. Cancer Res 65: 8975-8983, 2005.

83. Erdal H, Berndtsson M, Castro J, Brunk UT, Shoshan MC and Linder S: Induction of lysosomal membrane permeabilization by compounds that activate p53-independent apoptosis. Proc Natl Acad Sci USA 102: 192-197, 2005.

84. El-Rayes BF, Grignon R, Aslam N, Aranha O and Sarkar FH: Ciprofloxacin inhibits cell growth and synergises the effect of etoposide in hormone resistant prostate cancer cells. Int J Oncol 21: 207-211, 2002.

85. Fehrenbacher N and Jäättela M: Lysosomes as targets for cancer therapy. Cancer Res 65: 2993-2995, 2005. 